Article

\title{
Non-Chloride in Situ Preparation of Nano-Cuprous Oxide and Its Effect on Heat Resistance and Combustion Properties of Calcium Alginate
}

\author{
Peiyuan Shao ${ }^{1}$, Peng $X u^{1}$, Lei Zhang ${ }^{1,2}$, Yun Xue ${ }^{1}$, Xihui Zhao ${ }^{1}$, Zichao Li ${ }^{1,2, *(D)}$ and \\ Qun Li 1,3,*iD \\ 1 College of Chemistry and Chemical Engineering, Qingdao University, Qingdao 266071, China; \\ 15666681178@163.com (P.S.); X1627271005@163.com (P.X.); 2017020832@qdu.edu.cn (L.Z.); \\ xueyun@qdu.edu.cn (Y.X.); zhaoxihui@qdu.edu.cn (X.Z.) \\ 2 College of Life Sciences, Institute of Advanced Cross-Field Science, Qingdao University, \\ Qingdao 266071, China \\ 3 Shandong Collaborative Innovation Center of Marine Biobased Fibers and Ecological Textiles, \\ Qingdao University, Qingdao 266071, China \\ * $\quad$ Correspondence: zichaoli@qdu.edu.cn (Z.L.); qunli@qdu.edu.cn (Q.L.); Tel.: +86-532-8595-0705 (Q.L.)
}

Received: 11 October 2019; Accepted: 24 October 2019; Published: 27 October 2019

\begin{abstract}
With $\mathrm{Cu}^{2+}$ complexes as precursors, nano-cuprous oxide was prepared on a sodium alginate template excluded of $\mathrm{Cl}^{-}$and based on which the calcium alginate/nano-cuprous oxide hybrid materials were prepared by a $\mathrm{Ca}^{2+}$ crosslinking and freeze-drying process. The thermal degradation and combustion behavior of the materials were studied by related characterization techniques using pure calcium alginate as a comparison. The results show that the weight loss rate, heat release rate, peak heat release rate, total heat release rate and specific extinction area of the hybrid materials were remarkably lower than pure calcium alginate, and the flame-retardant performance was significantly improved. The experimental data indicates that nano-cuprous oxide formed a dense protective layer of copper oxide, calcium carbonate and carbon by lowering the initial degradation temperature of the polysaccharide chain during thermal degradation and catalytically dehydrating to char in the combustion process, and thereby can isolate combustible gases, increase carbon residual rates, and notably reduce heat release and smoke evacuation.
\end{abstract}

Keywords: alginate; non-chloride in situ preparation; nano-cuprous oxide; flame-retardant; mechanism

\section{Introduction}

Nano-cuprous oxide is a typical p-type semiconductor material with active electron holes, which exhibits effective catalytic activity, strong adsorption and low-temperature paramagnetic properties [1]. It has potential applications in organic synthesis, photoelectric conversion, new energy, water decomposition, sterilization, superconductivity, and others, and has become one of the most widely studied inorganic nanomaterials in the past decade [2-10].

Due to their low cost and sustainability, marine biomaterials from renewable resources have attracted attention today as fossil energy is depleting. Alginate is a linear, binary-block copolymer with special structures and properties [11,12]. It has served as a template for the preparation of new functional hybrid materials in recent years [13-17]. In particular, sodium alginate can form a strong and stable "egg box" model (Figure 1) $[12,18,19]$ structure of water-insoluble materials by crosslinking with divalent or trivalent metal ions, which is not only widely used in food and medicine [20-22], but also as an eco-friendly flame-retardant material [23-27]. 


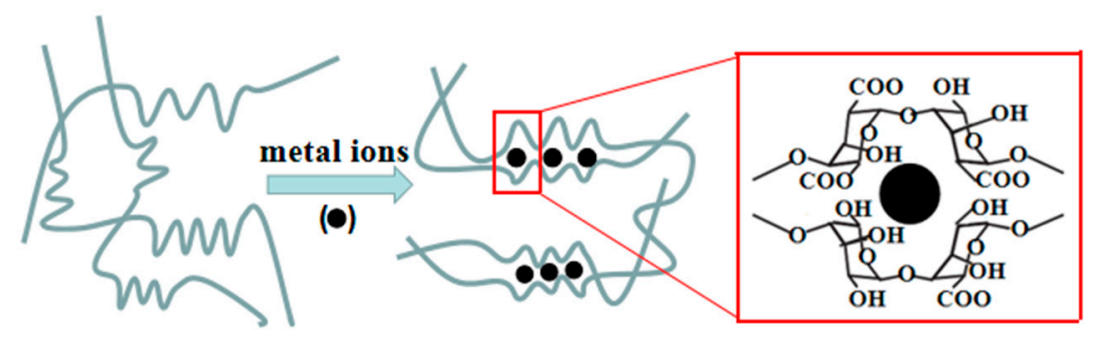

Figure 1. The crosslinking of sodium alginate—the "egg box" structure.

It is well known that the goal of developing hybrid materials is to improve the functionality of the hybrid material by creating a synergistic effect through the interaction between two phases [13,28-30], and the flame-retardant properties of the inherently flame-retardant calcium alginate can be further improved by adding inorganic nanoparticles [31-35]. In order to overcome the defects caused by the agglomeration of inorganic nanoparticles due to the mechanical addition method [34], previous research on preparing calcium alginate-based hybrid materials by in situ methods have been reported [31-33]. Herein, a new multifunctional material employing nano-cuprous oxide to improve the antibacterial and catalytic properties of calcium alginate is presented. However, to the best of our knowledge, no such report has been well documented so far. Note that copper alginate shows no flame retardancy [36]; thus, the effect of nano-cuprous oxide on the flame-retardant properties of calcium alginate is worth exploring.

Generally, calcium chloride has been used as a crosslinking agent to prepare calcium alginate. However, since copper ions, cuprous ions, and chloride ions have complicated chemical reactions, it is difficult to prepare calcium alginate/nano-cuprous oxide hybrid materials by such a method based on the attempts in our laboratory for over a year. Therefore, we propose a novel "non-chlorine in situ" preparation method, aiming for the facile preparation of calcium alginate/nano-cuprous oxide hybrid materials by the in situ method in the absence of chloride ions. Our study found an improved limiting oxygen index of 54.0 for the hybrid material compared to pure calcium alginate. Although the role of inorganic nanoparticles in hybrid material has been reported so far, there has been no literature on the effects of nano-cuprous oxide on the flame-retardant properties of calcium alginate or its mechanism. The results here show that the peak heat release rate of calcium alginate can be reduced by $15 \%$ with only $1 \mathrm{wt} \%$ nano-cuprous oxide addition, and the flame-retardant mechanism was slightly different from the traditional mechanism [5,7]. In summary, the calcium alginate/nano-cuprous oxide hybrid materials prepared by the "non-chlorine in situ" method is a multi-functional material with important potential applications and flame-retardant, antibacterial, and catalytic properties. The effect and mechanism of cuprous oxide on the material is essential to the design of the material.

\section{Materials and Methods}

\subsection{Materials}

Sodium alginate (NaAlg) was purchased from the Guangfu Fine Chemical Research Institute (Tianjin, China). Pentahydrate copper sulfate $\left(\mathrm{CuSO}_{4} \cdot 5 \mathrm{H}_{2} \mathrm{O}\right)$ was obtained from the Guangcheng Chemical Reagent Co., Ltd. (Tianjin, China). Both ammonia water $\left(\mathrm{NH}_{3} \cdot \mathrm{H}_{2} \mathrm{O}\right)$ and sodium hydroxide $(\mathrm{NaOH})$ were supplied by the fine chemical plant of the Laiyang Economic and Technological Development Zone (Yantai, China). Calcium acetate and ascorbic acid were purchased from Sinopharm Chemical Reagent Co., Ltd. (Shanghai, China). All the chemicals were of analytical grade and not further purified, and all the solutions were prepared using deionized water.

\subsection{Preparation of $\mathrm{Nano}_{-} \mathrm{Cu}_{2} \mathrm{O}$ In Situ}

The preparation process of the nano- $\mathrm{Cu}_{2} \mathrm{O}$ is shown schematically in Scheme 1 . $\mathrm{CuSO}_{4} \cdot 5 \mathrm{H}_{2} \mathrm{O}$ $(3.9 \mathrm{~g})$ was dissolved in a predetermined amount of deionized water, followed by the addition of $13 \mathrm{~mL} \mathrm{NH}_{3} \cdot \mathrm{H}_{2} \mathrm{O}(12 \mathrm{~mol} / \mathrm{L})$. Then, $20 \mathrm{~g}$ of NaAlg was added and the whole volume of the mixture 
solution was maintained at $500 \mathrm{~mL}$. The solution was heated at a constant temperature of $55^{\circ} \mathrm{C}$ for $6 \mathrm{~h}$ until a uniform and stable blue solution was formed. Subsequently, $11.4 \mathrm{~g}$ of ascorbic acid was added into the solution and was slowly stirred until the color entirely changed to yellow. Consequently, the nano- $\mathrm{Cu}_{2} \mathrm{O}$ was prepared on the NaAlg template.

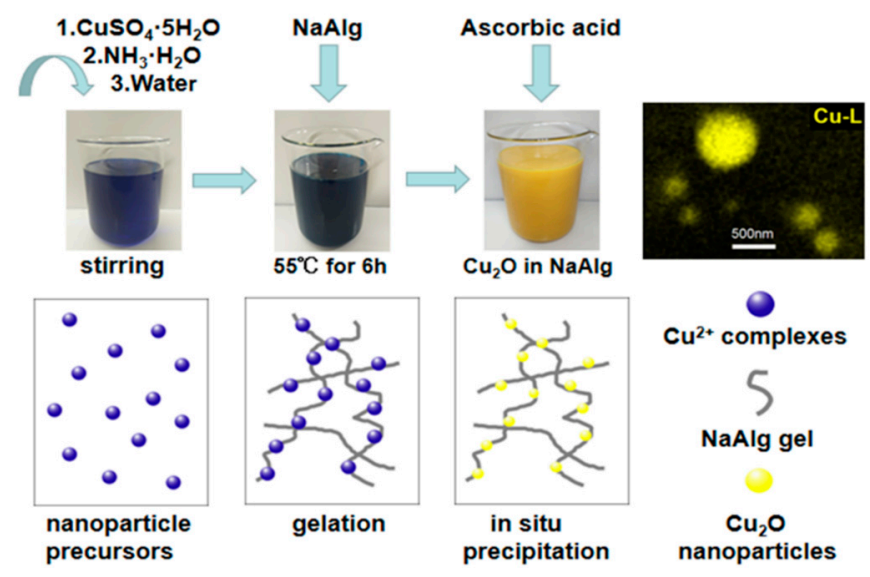

Scheme 1. Schematic of nano- $\mathrm{Cu}_{2} \mathrm{O}$ preparation in situ.

\subsection{Preparation of Calcium Alginate/Nano-Cuprous Oxide Hybrid Materials}

$\mathrm{NaOH}(1 \mathrm{~mol} / \mathrm{L})$ was slowly dropped into the $3 \mathrm{wt} \%$ calcium acetate solution $(2 \mathrm{~L})$ until the $\mathrm{pH}$ reached 10. The as-prepared solution containing $4 \mathrm{wt} \% \mathrm{NaAlg}$ was poured into molds of various shapes and then placed in the calcium acetate solution for $24 \mathrm{~h}$, obtaining the crosslinked hybrid material $\left(\mathrm{CaAlg} /\right.$ nano- $\left.\mathrm{Cu}_{2} \mathrm{O}\right)$. Finally, the product was washed several times with deionized water and dried in a freeze-dryer for $24 \mathrm{~h}$. It is found by calculation that the content of $\mathrm{Cu}_{2} \mathrm{O}$ in the hybrid material prepared by the in situ method was equivalent to the mechanical process of adding of $1 \mathrm{wt} \%$ $\mathrm{Cu}_{2} \mathrm{O}$. As a comparison, pure calcium alginate $(\mathrm{CaAlg})$ was prepared in a similar procedure only without the addition of the reagents related to the preparation of $\mathrm{Cu}_{2} \mathrm{O}$.

\subsection{Measurements and Characterizations}

For the characterization of the calcined residue, the samples were heated to a target temperature $\left(250,450\right.$, and $\left.750^{\circ} \mathrm{C}\right)$ at a heating rate of $5^{\circ} \mathrm{C} / \mathrm{min}$ in air, and then kept for $2 \mathrm{~h}$.

\subsubsection{Density}

The quality and dimension of $\mathrm{CaAlg}$ and $\mathrm{CaAlg} /$ nano- $\mathrm{Cu}_{2} \mathrm{O}$ hybrid material were measured using an electronic balance (PL303 Precision Balance, Mettler-Toledo, Tokyo, Japan) and digital calipers, and then the densities were calculated based on the data.

\subsubsection{X-ray Diffraction (XRD)}

An X-ray diffractometer (Ultima IV, Rigaku, Tokyo, Japan) was employed to investigate the samples and calcined residue under $\mathrm{Cu} \mathrm{K} \alpha$ radiation $(\lambda=0.15418 \mathrm{~nm})$, with a scan rate $(2 \theta)$ of $5^{\circ} / \mathrm{min}$ in an angular range of 15-80 in continuous mode (operating voltage: $40 \mathrm{kV}$, current: $30 \mathrm{~mA}$ ).

\subsubsection{Field Emission Scanning Electron Microscopy (FESEM)}

The morphology and microstructure of the materials and their calcined residues were observed by a field emission scanning electron microscope (Sigma 500/VP, Carl Zeiss AG, Jena, Germany) at a beam voltage of $10 \mathrm{kV}$. Prior to SEM imaging, all the sample surfaces were sprayed with thin layers of gold to avoid charging under the electron beam. The distribution of $\mathrm{Cu}$ on the surface of the $\mathrm{CaAlg} / \mathrm{nano}^{-} \mathrm{Cu}_{2} \mathrm{O}$ hybrid material was plotted using an energy dispersive X-ray spectrometer (EDX) attachment. 


\subsubsection{Synchronous Thermal Analyzer (STA)}

A synchronous thermal analyzer (TGA/DSC1 1600, Mettler Toledo, Columbus, OH, USA) was employed to analyze the materials under a nitrogen atmosphere. Samples of 4-6 mg were placed in an aluminum crucible and heated from room temperature to $1000{ }^{\circ} \mathrm{C}$ at a heating rate of $10^{\circ} \mathrm{C} / \mathrm{min}$ and a gas flow rate of $50 \mathrm{~mL} / \mathrm{min}$.

\subsubsection{Cone Calorimeter (CONE)}

The combustion behavior of the samples was studied with a cone calorimeter (FTT-0007, Fire Testing Technology, East Grinstead, UK) under an external heat flux of $50 \mathrm{~kW} / \mathrm{m}^{2}$ with horizontal orientation in air according to standard ISO 5660-1. The dimensions of all the samples were $100 \mathrm{~mm} \times 100 \mathrm{~mm} \times 8 \mathrm{~mm}$.

\subsubsection{Limiting Oxygen Index (LOI)}

The LOI values were determined using a M606B type instrument (Shanfang Instrument Co., Ltd., Qingdao, China). Samples of dimensions $80 \mathrm{~mm} \times 10 \mathrm{~mm} \times 8 \mathrm{~mm}$ were used for all the tests while $\mathrm{CaAlg} /$ nano- $-\mathrm{Cu}_{2} \mathrm{O}$ was compressed to ensure that it was substantially the same quality as CaAlg. The samples were placed in a standard laboratory, at a temperature of $23 \pm 2{ }^{\circ} \mathrm{C}$ and a relative humidity of $50 \pm 5 \%$, for at least $24 \mathrm{~h}$ before testing.

\subsubsection{Vertical Burning (UL-94)}

Vertical burning tests were performed on a CZF-2 test instrument (Jiangning Analytical Instrument Factory, Nanjing, China) according to the standard American Society for Testing and Materials (ASTM) D3801. The size of both samples was $130 \mathrm{~mm} \times 13 \mathrm{~mm} \times 8 \mathrm{~mm}$.

\subsubsection{Microscale Combustion Calorimeter (MCC)}

A microscale combustion calorimeter (MCC-2, Govmark, Farmingdale, NY, USA) was used to investigate the flammability behavior of the test samples. Samples of $5 \pm 0.05 \mathrm{mg}$ were heated from room temperature to $750{ }^{\circ} \mathrm{C}$ (heating rate of $1{ }^{\circ} \mathrm{C} / \mathrm{s}$ ) in a stream of nitrogen flowing at $80 \mathrm{~cm}^{3} / \mathrm{min}$. Before entering a $900{ }^{\circ} \mathrm{C}$ combustion furnace, the thermal degradation products were mixed with a $20 \mathrm{~cm}^{3} /$ min steam, consisting of $20 \%$ oxygen and $80 \%$ nitrogen.

\section{Results and Discussion}

\subsection{Morphology of Materials}

In Figure 2a, the digital photo shows that the two materials exhibited similar porous structures with notably different colors. The difference in color can be attributed to the fact that nano- $\mathrm{Cu}_{2} \mathrm{O}$ changed the optical properties of the material itself, which was dependent on the structure, size, and dispersion of the particles [13]. The freeze-drying condensed the moisture in the material into ice, and the "ice matrix" left after the sublimation of the ice was the essence of its macroscopic appearance as a porous structure [37,38]. 

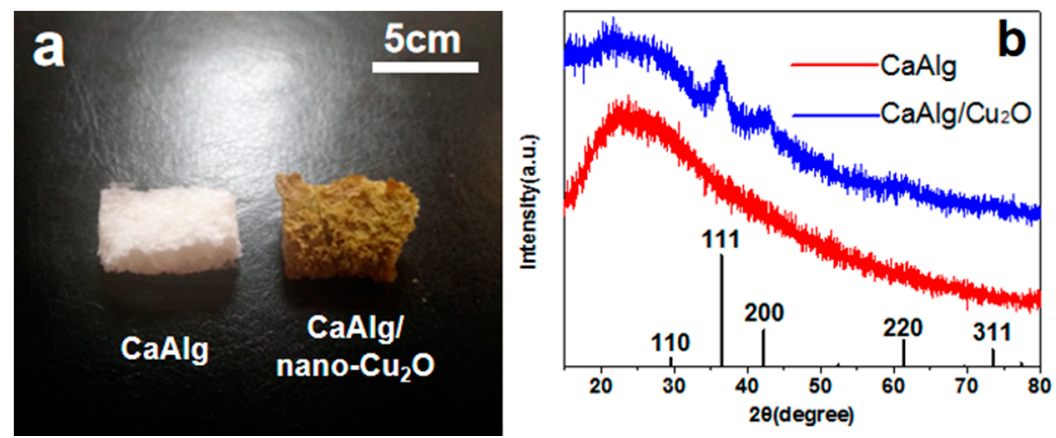

Figure 2. Digital photos (a) and X-ray diffraction (XRD) patterns (b) of CaAlg and CaAlg/nano- $\mathrm{Cu}_{2} \mathrm{O}$.

The two materials were analyzed by XRD and the results are shown in Figure 2b. Comparing the obtained diffraction peak with the pure phase $\mathrm{Cu}_{2} \mathrm{O}$ (cuprite, JCPDS-\#99-0041), it was found that the four peaks with different diffraction values of two materials (at $36.4^{\circ}, 42.3^{\circ}, 61.4^{\circ}$ and $73.5^{\circ}$ ) were identical with the crystal planes of $\mathrm{Cu}_{2} \mathrm{O}$ at (111), (200), (220), and (311), respectively. This confirms the existence of $\mathrm{Cu}_{2} \mathrm{O}$ and also the formation of hybrid materials.

It is noteworthy that the density of $\mathrm{CaAlg}$ was $0.19 \mathrm{~g} / \mathrm{cm}^{3}$ while that of $\mathrm{CaAlg} / \mathrm{nano}-\mathrm{Cu}_{2} \mathrm{O}$ hybrid material was only $0.08 \mathrm{~g} / \mathrm{cm}^{3}$. FESEM was used to study the morphology of the two materials in order to explain the difference in density. The results of electron microscopic characterization are shown in Figure 3. It can be seen from the analysis and comparison of the SEM images that CaAlg showed a lamellar structure with a smooth, uniform surface and a few nodules. $\mathrm{CaAlg} / \mathrm{nano}-\mathrm{Cu}_{2} \mathrm{O}$ was a three-dimensional network structure, and some spherical $\mathrm{Cu}_{2} \mathrm{O}$ particles with an average diameter below $100 \mathrm{~nm}$ were adhered to the CaAlg framework interface through a strong interaction, while the others were embedded in the framework of CaAlg.

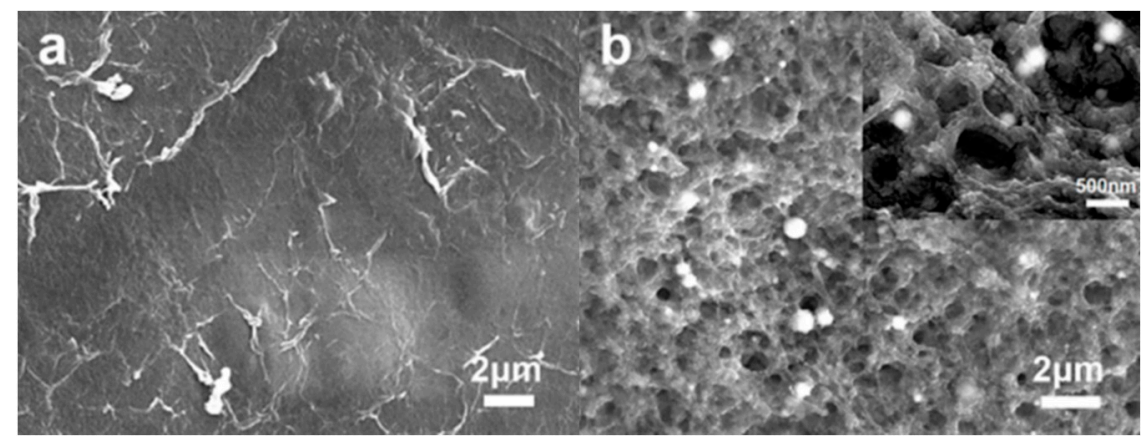

Figure 3. Scanning electron microscopy (SEM) images of (a) CaAlg and (b) CaAlg/nano-Cu $2 \mathrm{O}$. The inset in $(\mathbf{b})$ is the magnified image.

It can be noticed from the microstructure that there were differing densities between the two materials and the three-dimensional network structure clearly exhibited a relatively lower density. The formation of this type of structure is due to the fact that NaAlg itself is rich in hydroxyl and carboxyl groups and can form intermolecular hydrogen bonds with $\mathrm{Cu}_{2} \mathrm{O}$ in situ $[39,40]$. The continuous network structure formed at the same time affected the mass transfer process of the solid-liquid phases in subsequent crosslinking, which led to the presence of a similar three-dimensional network structure in the final hybrid materials. This structure can effectively prevent the movement of polymer molecular chains during combustion with a lower thermal conductivity, and thus can provide better thermal stability of the materials [11,41]. 


\subsection{Thermal Stability}

The thermal stability of $\mathrm{CaAlg}$ and $\mathrm{CaAlg} / \mathrm{nano}-\mathrm{Cu}_{2} \mathrm{O}$ was investigated by simultaneous thermal analysis (TG-DSC) and the comparison curves are displayed in Figure 4. The studied samples followed the same degradation trend and tended to be stable after three stages of decline. The decomposition process of CaAlg was similar to that of previous studies [31,42], and the three stages of its decomposition included: the desorption process of water at $50-140^{\circ} \mathrm{C}$, the thermal destruction of glycosidic bonds and the elimination process of adjacent hydroxyl groups at $240-400^{\circ} \mathrm{C}$; and a process took place in which the glycosidic bond was further destroyed to form an intermediate substance at $400-520^{\circ} \mathrm{C}$.

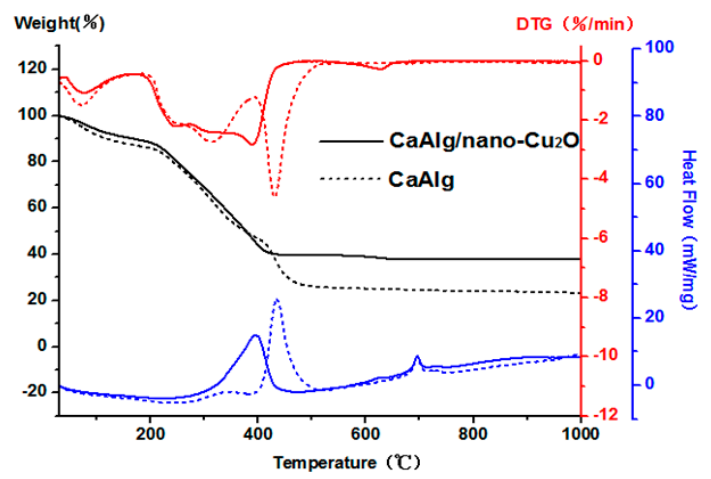

Figure 4. Weight loss, DTG, and DSC curves of CaAlg and CaAlg/nano- $\mathrm{Cu}_{2} \mathrm{O}$ under $\mathrm{N}_{2}$.

Comparing the two materials, the thermal stability of $\mathrm{CaAlg} / \mathrm{nano}-\mathrm{Cu}_{2} \mathrm{O}$ was obviously better than that of $\mathrm{CaAlg}$, and the rate of weight loss was reduced by about $15 \%$. In the desorption stage of water, the weight loss rate of $\mathrm{CaAlg} / \mathrm{nano}-\mathrm{Cu}_{2} \mathrm{O}$ was significantly lower than that of $\mathrm{CaAlg}$, which can be attributed to the low thermal conductivity for the three-dimensional network structure of the hybrid material. As a biogenic polymer, CaAlg is rich in hydroxyl and carboxyl groups and can easily absorb water, while for hybrid materials, $\mathrm{Cu}_{2} \mathrm{O}$ can form multi-hydrogen bonds with the hydroxyl and carboxyl groups in $\mathrm{CaAlg}$, so that the composites had a better thermal stability at low temperature.

As shown in Figure 4, more notable differences occurred at around $400{ }^{\circ} \mathrm{C}$, in which $\mathrm{CaAlg} /$ nano- $\mathrm{Cu}_{2} \mathrm{O}$ was the first to re-decompose the glycosidic bonds at $360{ }^{\circ} \mathrm{C}$, almost $40{ }^{\circ} \mathrm{C}$ less than $\mathrm{CaAlg}$. This was mainly due to the fact that $\mathrm{Cu}_{2} \mathrm{O}$ in the hybrid material catalyzed the thermal decomposition of CaAlg and reduced the energy required for the reaction [43]. Comparing the DSC curves, it was found that although the decomposition reaction of $\mathrm{CaAlg} /$ nano- $\mathrm{Cu}_{2} \mathrm{O}$ proceeded in advance, the peak exotherm was significantly lower than that of CaAlg (namely 38.8\%). The decrease in peak heat release indicated improvement in the thermal stability of the material.

In addition, there were two other noticeable observations in the curves shown in Figure 4. The slight weight loss of $\mathrm{CaAlg} / \mathrm{nano}-\mathrm{Cu}_{2} \mathrm{O}$ at $600{ }^{\circ} \mathrm{C}$ led to a weak change in the heat flux, which may be due to the decomposition of $\mathrm{CaCO}_{3}$ in the thermal cracking products of $\mathrm{CaAlg}$ catalyzed by $\mathrm{CuO}$. It can be observed from the DSC curves that the two materials exhibited exothermic peaks at $700{ }^{\circ} \mathrm{C}$ without causing mass loss, which can be attributed to the phase transition process of the intermediate produced by the thermal decomposition of $\mathrm{CaAlg}$ at high temperature.

The XRD analysis of the calcined residue of the two prepared materials was carried out and the results are shown in Figure 5. It can be seen that $\mathrm{CaAlg} /$ nano- $^{-} \mathrm{u}_{2} \mathrm{O}$ showed a diffraction peak of $\mathrm{Cu}_{2} \mathrm{O}$ (cuprite, JCPDS-\#99-0041) only in the calcination residue at $250{ }^{\circ} \mathrm{C}$. However, in the calcination residue under the three temperature conditions, clear $\mathrm{CuO}$ (copper oxide, JCPDS-\#89-5898) diffraction peaks can be observed, which were formed by the oxidation of $\mathrm{Cu}_{2} \mathrm{O}$ in the material. Except for $\mathrm{Cu}_{2} \mathrm{O}$ and $\mathrm{CuO}$, the components of the calcined residue of the two materials were basically the same. 

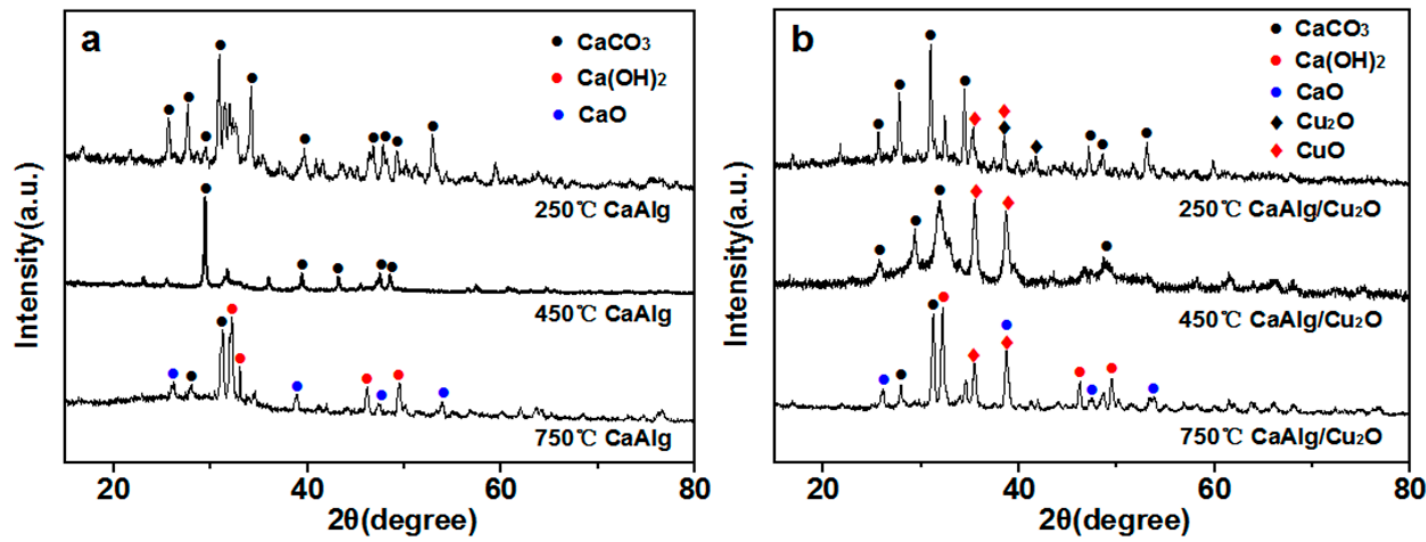

Figure 5. XRD patterns of calcined residue at different temperatures: (a) $\mathrm{CaAlg}$ and (b) $\mathrm{CaAlg} / \mathrm{nano}-\mathrm{Cu}_{2} \mathrm{O}$ hybrid material.

Among them, one category of product was $\mathrm{CaCO}_{3}$ of different crystal phases at $250{ }^{\circ} \mathrm{C}$, including calcite (calcite, JCPDS-\#99-0022), aragonite (aragonite, JCPDS-\#71-2392) and vaterite (vaterite, JCPDS-\#74-1867), while the product was at a single calcite phase of $\mathrm{CaCO}_{3}$ at $450{ }^{\circ} \mathrm{C}$. With the decomposition of $\mathrm{CaCO}_{3}$ at $750{ }^{\circ} \mathrm{C}$, not only $\mathrm{CaCO}_{3}$ but also $\mathrm{CaO}$ and $\mathrm{Ca}(\mathrm{OH})_{2}$ were generated.

Through the morphological study of the residue after calcination of the two materials, the stability of the materials was analyzed from a microscopic point of view. The relevant characterization results are shown in Figure 6.
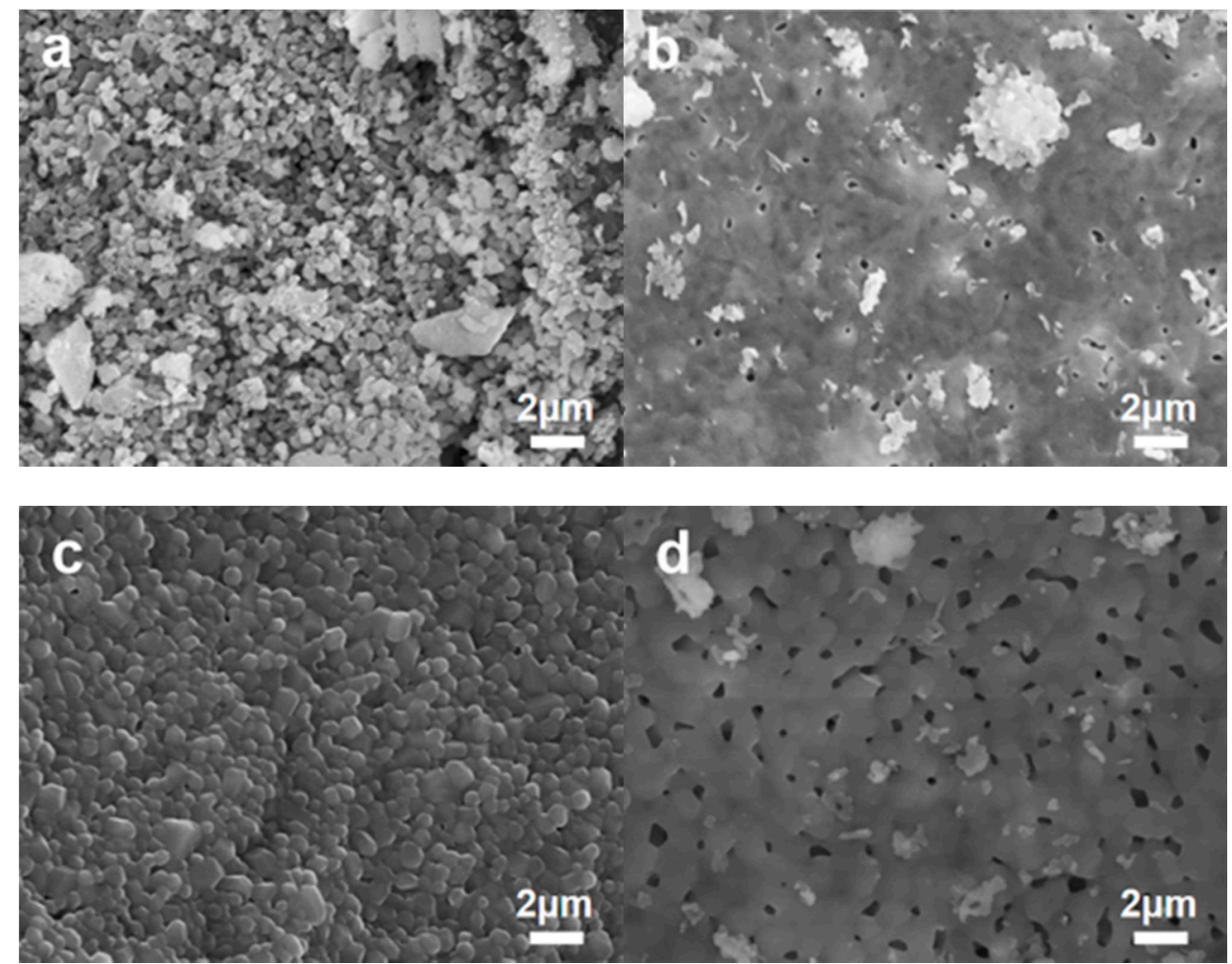

Figure 6. SEM images of calcined residue: (a) CaAlg heated to $250{ }^{\circ} \mathrm{C}$; (b) $\mathrm{CaAlg} /$ nano- $\mathrm{Cu}_{2} \mathrm{O}$ heated to $250{ }^{\circ} \mathrm{C}$; (c) CaAlg heated to $750{ }^{\circ} \mathrm{C}$; (d) $\mathrm{CaAlg} /$ nano- $\mathrm{Cu}_{2} \mathrm{O}$ heated to $750{ }^{\circ} \mathrm{C}$.

As shown in Figure $6 \mathrm{a}, \mathrm{CaCO}_{3}$ particles of different sizes were distributed on the surface of the $\mathrm{CaAlg}$ calcination residue at $250^{\circ} \mathrm{C}$. However, for $\mathrm{CaAlg} /$ nano- $\mathrm{Cu}_{2} \mathrm{O}$, the framework of CaAlg collapsed as the temperature rose and $\mathrm{Cu}_{2} \mathrm{O}$ particles with a higher surface energy were rapidly deposited on 
the surface of the material, which was oxidized to $\mathrm{CuO}$. As seen in Figure $6 \mathrm{~b}, \mathrm{Cu}_{2} \mathrm{O}$ catalyzed the decomposition reaction of the outer layer of $\mathrm{CaAlg}$, in which the release of gas carried off most of the heat and the remaining solid residue formed a dense barrier on the outer layer. The formation of the barrier layer can prevent heat and combustible gas from diffusing into the internal layer [44], greatly reducing the heat release rate and significantly improving the flame retardancy.

It can be observed from Figure $6 \mathrm{c}$ that dense polyhedral particles covered the surface of the CaAlg calcination residue at $750{ }^{\circ} \mathrm{C}$, demonstrating the flame-retardant properties of the material. However, the most obvious morphological change in the calcination residue of $\mathrm{CaAlg} / \mathrm{nano}-\mathrm{Cu}_{2} \mathrm{O}$ was the inflation of the residue particles [45], as displayed in Figure 6d, which directly formed denser particle distribution and smaller surface voids. This can further improve the flame retardancy of the material. The morphological difference was related to the carbonized layer formation of the CuO-promoted material at high temperature $[11,28]$.

\subsection{Combustion Behavior}

The experimental data of cone calorimetry are listed in Table 1. As seen, the heat release rate (HRR), peak heat release rate (PHRR), and total heat of release (THR) of CaAlg/nano- $\mathrm{Cu}_{2} \mathrm{O}$ were significantly lower than those of CaAlg. However, the quality of the samples used in this test was quite different due to the various structures, making the comparison of data inconclusive. At present, there is no known study on the influence of sample differences on cone calorimetry data and the degree of the relevant influence. Thus, the subsequent data were reanalyzed using an MCC experiment.

Table 1. CONE test results of $\mathrm{CaAlg}$ and $\mathrm{CaAlg} /$ nano- $\mathrm{Cu}_{2} \mathrm{O} . \mathrm{HRR}=$ heat release rate; $\mathrm{THR}=$ total heat of release; $\mathrm{PHRR}=$ peak heat release rate; $\mathrm{EHC}=$ effective heat of combustion; $\mathrm{SEA}=$ specific extinction area.

\begin{tabular}{|c|c|c|c|c|c|c|}
\hline Samples & TTI (s) & $\begin{array}{c}\text { HRR } \\
\left(\mathrm{kW} / \mathrm{m}^{2}\right)\end{array}$ & $\begin{array}{c}\text { THR } \\
\left(\mathrm{MJ} / \mathrm{m}^{2}\right)\end{array}$ & $\begin{array}{c}\text { PHRR } \\
\left(\mathrm{kW} / \mathrm{m}^{2}\right)\end{array}$ & $\begin{array}{c}\text { EHC } \\
(\mathrm{MJ} / \mathrm{kg})\end{array}$ & $\begin{array}{c}\text { Mean SEA } \\
\left(\mathrm{m}^{2} / \mathrm{kg}\right)\end{array}$ \\
\hline CaAlg & 11 & 39.73 & 6.40 & 93.59 & 10.87 & 41.46 \\
\hline $\mathrm{CaAlg} /$ nano- $\mathrm{Cu}_{2} \mathrm{O}$ & 6 & 16.09 & 2.02 & 67.30 & 9.14 & 21.43 \\
\hline
\end{tabular}

There are two quality-independent parameters in the CONE test-effective heat of combustion (EHC) and mean specific extinction area (mean SEA) — which are reliable results worthy of attention. $\mathrm{EHC}$ represents the ratio of HRR to mass loss rate, reflecting the degree of combustion of volatile gases in the gas phase flame. By comparison, it can be found that $\mathrm{CaAlg} / \mathrm{nano}-\mathrm{Cu}_{2} \mathrm{O}$ had a lower $\mathrm{EHC}$ value than that of $\mathrm{CaAlg}$, indicating that the overall response of the former was lower than that of the latter, which indirectly proved that the hybrid material had better thermal stability. SEA is defined as the ability of a sample to decompose volatiles produced by flammable masses of combustibles. By comparing the mean SEA of the two materials, it can be clearly seen that $\mathrm{CaAlg} / \mathrm{nano}^{-} \mathrm{Cu}_{2} \mathrm{O}$ exhibited better prominent smoke suppression ability than CaAlg.

Table 2 shows the results of the LOI and UL-94 tests for the two materials. In the UL-94 test, both materials were classified as V-0 based on the fact that both of them exhibited smoldering and maintained their original shape without melt dripping. For the limiting oxygen experiment, the materials are considered to be flame retardant when the LOI value surpasses 27.0. The LOI value of CaAlg was 49.2, which can be already recognized as well flame-retardant. Comparatively, the LOI value of $\mathrm{CaAlg} /$ nano- $\mathrm{Cu}_{2} \mathrm{O}$ reached 54.0, reflecting a successful improvement by introducing the nano-Cu2O particles to CaAlg. 
Table 2. Limiting oxygen index (LOI) test, UL-94 test and MCC test results of CaAlg and $\mathrm{CaAlg} /$ nano- $\mathrm{Cu}_{2} \mathrm{O}$.

\begin{tabular}{ccccccc}
\hline Samples & LOI (\%) & UL-94 & HRC (J/g/K) & PHRR (W/g) & THR (kJ/g) & Residues (\%) \\
\hline CaAlg & 49.2 & V-0 & 18 & 16.19 & 4.3 & 55.65 \\
CaAlg/nano-Cu $2 \mathrm{O}$ & 54.0 & V-0 & 16 & 14.01 & 4 & 60.55 \\
\hline
\end{tabular}

MCC, also known as pyrolysis combustion flow calorimetry, is a standard ASTM test method (ASTM 7309) for the analysis of solid materials. It can dynamically measure the HRR and other relevant data based on the oxygen consumed during the experiment [24]. The material can be tested and analyzed at milligram sizes, which can effectively avoid the influence caused by differences in sample preparation [46].

As seen in Table 2, the MCC results are consistent with the phenomenon of the flame experiments. CaAlg had a HRC of $18 \mathrm{~J} / \mathrm{g} / \mathrm{K}$, a PHRR of $16.19 \mathrm{~W} / \mathrm{g}$, and a THR of $4.3 \mathrm{~kJ} / \mathrm{g}$, all of which were at lower levels. The fabrication of $\mathrm{CaAlg} / \mathrm{nano}^{-} \mathrm{Cu}_{2} \mathrm{O}$ further improved the flame retardancy of $\mathrm{CaAlg}$, and the values of several parameters declined, especially for the PHRR, which was decreased by nearly $15 \%$. At the same time, the $5 \%$ increase in residual carbon confirmed the effect of the nanoparticles on the catalytic carbon formation of $\mathrm{CaAlg} /$ nano- $\mathrm{Cu}_{2} \mathrm{O}$ as well. It is clear that nano- $\mathrm{Cu}_{2} \mathrm{O}$ showed positive influence on the flame retardancy of the hybrid materials.

\subsection{Flame-Retardant Mechanism}

Scheme 2 shows the flame-retardant mechanism of nano- $\mathrm{Cu}_{2} \mathrm{O}$ on the $\mathrm{CaAlg} /$ nano- $\mathrm{Cu}_{2} \mathrm{O}$ hybrid material in detail. Due to the presence of inorganic nanoparticles, the hybrid materials formed a three-dimensional network structure with low thermal conductivity, which showed superior thermal stability at the initial stage of combustion.

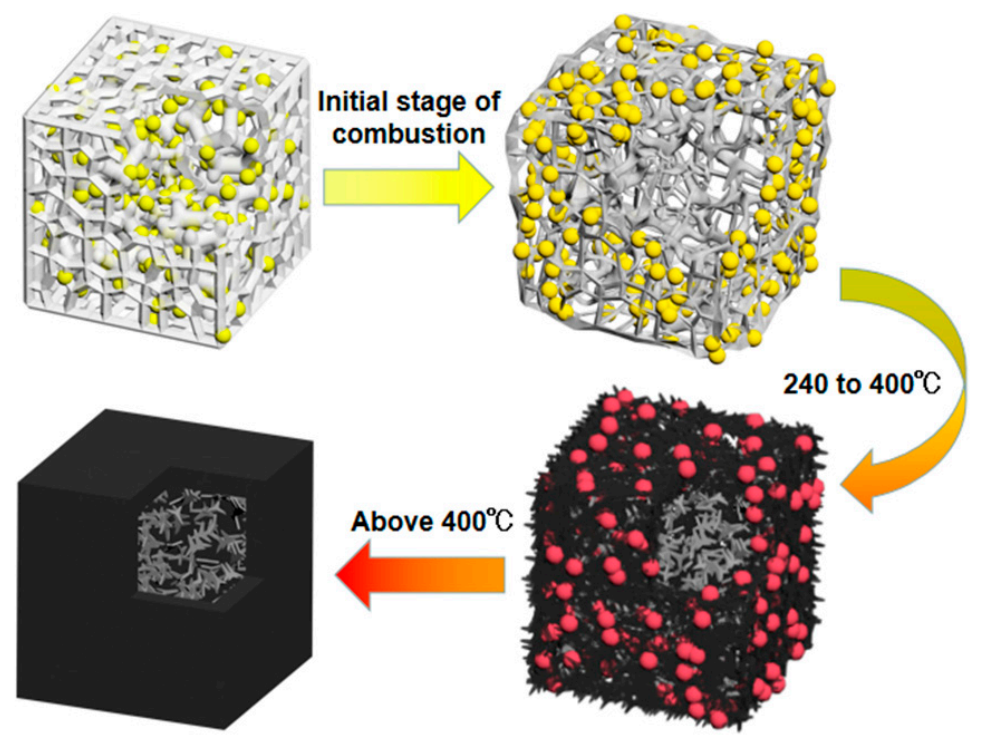

Scheme 2. Flame-retardant mechanism of nano- $\mathrm{Cu}_{2} \mathrm{O}$ on the hybrid materials.

At $40-400{ }^{\circ} \mathrm{C}$, the skeleton of CaAlg gradually collapsed and disintegrated with the increase of temperature. The nano- $\mathrm{Cu}_{2} \mathrm{O}$ attached to the skeleton had a high surface energy and rapidly migrated and deposited on the surface of $\mathrm{CaAlg} /$ nano- $\mathrm{Cu}_{2} \mathrm{O}$. Since $\mathrm{Cu}_{2} \mathrm{O}$ catalyzed the thermal decomposition reaction of $\mathrm{CaAlg}$, the outermost $\mathrm{CaAlg}$ is the first to be decomposed at a relatively low temperature. Vapor and $\mathrm{CO}_{2}$ generated by dehydration and decarboxylation in the CaAlg thermal decomposition process carried away most of the heat, while the remaining solid residue, including $\mathrm{CuO}$ oxidized from $\mathrm{Cu}_{2} \mathrm{O}$, formed a dense carbon barrier in the outermost layer of $\mathrm{CaAlg} / \mathrm{nano}-\mathrm{Cu}_{2} \mathrm{O}$. The barrier 
layer prevented heat and flammable gas from diffusing into the inner layer, while the release of the incombustible gas lowered the concentration of the flammable gas at both the inner and outer contact surfaces, suppressing the overall thermal decomposition reaction to a lower degree and greatly reducing the HRR.

Above $400{ }^{\circ} \mathrm{C}$, the thermal decomposition product $\mathrm{CaCO}_{3}$ began to shift to $\mathrm{CaO}$. As the temperature increased further, char formation began. At this time, the $\mathrm{CuO}$ in the calcination residue of $\mathrm{CaAlg} / \mathrm{nano}-\mathrm{Cu}_{2} \mathrm{O}$ became a catalyst for the char formation reaction. A large amount of the carbonaceous carbon produced was coated on the surface of $\mathrm{CaAlg} /$ nano- $\mathrm{Cu}_{2} \mathrm{O}$ and appeared to be an expansion of the calcination residue. It promoted a denser barrier layer and a narrower surface void that both shielded the diffusion of flammable gases and blocked heat and heat radiation. The heat feedback of the material was reduced, and thereby the progress of the combustion reaction was suppressed. This further improved the flame retardancy of the hybrid materials.

\section{Conclusions}

In this study, nano-cuprous oxide was prepared by employing $\mathrm{Cu}^{2+}$ complexes as precursors via a non-chloride in situ method rather than the widely used direct crosslinking of the sodium alginate solution template. Then, the composites based on the calcium alginate/cuprous oxide nanoparticles were fabricated by a simple green crosslinking and freeze-drying process. Measurements and characterizations show that $\mathrm{CaAlg} /$ nano- $\mathrm{Cu}_{2} \mathrm{O}$ displayed a completely different three-dimensional network structure from $\mathrm{CaAlg}$, with a LOI value up to 54.0 . The addition of a mere $1 \mathrm{wt} \%$ nano- $\mathrm{Cu}_{2} \mathrm{O}$ reduced the PHHR by $15 \%$ and increased the residual carbon rate by $5 \%$, which contributed to the improvement for the flame retardancy of $\mathrm{CaAlg} / \mathrm{nano}^{-} \mathrm{Cu}_{2} \mathrm{O}$. Moreover, it can be inferred from the supposed working and flame-retardant mechanism of nano- $\mathrm{Cu}_{2} \mathrm{O}$ on $\mathrm{CaAlg}$ that the carbon layer that formed at low temperature due to catalysis protected the internal material, reduced the HRR, THR, PHRR and EHC, and suppressed the release of smoke of the hybrid materials. The char formation was reinforced by $\mathrm{CuO}$ catalysis to reduce combustion performance and improve the flame-retardant properties of the material. $\mathrm{CaAlg} /$ nano- $\mathrm{Cu}_{2} \mathrm{O}$ not only has potential development prospects in the field of antibacterial and catalytic materials, but also a green material with lower heat release and smoke release, and improved flame-retardant properties compared to CaAlg.

Author Contributions: Conceptualization, Z.L. and Q.L.; Data curation, P.S.; Investigation, P.S., P.X. and L.Z.; Resources, Y.X. and X.Z.; Writing—original draft, P.S.; Writing—review and editing, Z.L.

Funding: This work was supported by the National Natural Science Foundation of China (grant number 51773102).

Acknowledgments: The authors wish to thank Tingting Zhang from Biology Experimental Teaching Center of College of Life Sciences in Qingdao University for the use of some instruments and assistance with the measurements.

Conflicts of Interest: The authors declare no conflict of interest.

\section{References}

1. Sun, S.; Zhang, X.; Yang, Q.; Liang, S.; Zhang, X.; Yang, Z. Cuprous oxide $\left(\mathrm{Cu}_{2} \mathrm{O}\right)$ crystals with tailored architectures: A comprehensive review on synthesis, fundamental properties, functional modifications and applications. Prog. Mater. Sci. 2018, 96, 111-173. [CrossRef]

2. Qiu, S.L.; Xing, W.Y.; Feng, X.M.; Yu, B.; Mu, X.W.; Yuen, R.K.K.; Hu, Y. Self-standing cuprous oxide nanoparticles on silica@polyphosphazene nanospheres: 3D nanostructure for enhancing the flame retardancy and toxic effluents elimination of epoxy resins via synergistic catalytic effect. Chem. Eng. J. 2017, 309, 802-814. [CrossRef]

3. Aguilar, M.S.; Rosas, G. A new synthesis of $\mathrm{Cu}_{2} \mathrm{O}$ spherical particles for the degradation of methylene blue dye. Environ. Nanotechnol. Monit. Manag. 2019, 11, 100195. [CrossRef]

4. Su, R.; Li, Q.; Chen, Y.; Gao, B.; Yue, Q.; Zhou, W. One-step synthesis of $\mathrm{Cu}_{2} \mathrm{O} @$ carbon nanocapsules composites using sodium alginate as template and characterization of their visible light photocatalytic properties. J. Clean. Prod. 2019, 209, 20-29. [CrossRef] 
5. Kumar, S.; Ojha, A.K.; Bhorolua, D.; Das, J.; Kumar, A.; Hazarika, A. Facile synthesis of CuO nanowires and $\mathrm{Cu}_{2} \mathrm{O}$ nanospheres grown on $\mathrm{rGO}$ surface and exploiting its photocatalytic, antibacterial and supercapacitive properties. Phys. B 2019, 558, 74-81. [CrossRef]

6. Kociolek-Balawejder, E.; Stanislawska, E.; Dworniczek, E.; Seniuk, A.; Jacukowicz-Sobala, I.; Winiarska, K. $\mathrm{Cu}_{2} \mathrm{O}$ doped gel-type anion exchanger obtained by reduction of brochantite deposit and its antimicrobial activity. React. Funct. Polym. 2019, 141, 42-49. [CrossRef]

7. Yang, Z.; Hao, X.; Chen, S.; Ma, Z.; Wang, W.; Wang, C.; Yue, L.; Sun, H.; Shao, Q.; Murugadoss, V.; et al. Long-term antibacterial stable reduced graphene oxide nanocomposites loaded with cuprous oxide nanoparticles. J. Colloid Interface Sci. 2019, 533, 13-23. [CrossRef]

8. Wang, D.; Kan, Y.; Yu, X.; Liu, J.; Song, L.; Hu, Y. In situ loading ultra-small Cu $\mathrm{Cu}_{2} \mathrm{O}$ nanoparticles on 2D hierarchical $\mathrm{TiO}_{2}$-graphene oxide dual-nanosheets: Towards reducing fire hazards of unsaturated polyester resin. J. Hazard. Mater. 2016, 320, 504-512. [CrossRef]

9. Guo, Y.; Dai, M.M.; Zhu, Z.X.; Chen, Y.Q.; He, H.; Qin, T.H. Chitosan modified $\mathrm{Cu}_{2} \mathrm{O}$ nanoparticles with high catalytic activity for p-nitrophenol reduction. Appl. Surf. Sci. 2019, 480, 601-610. [CrossRef]

10. Jing, G.J.; Zhang, X.J.; Zhang, A.A.; Li, M.; Zeng, S.H.; Xu, C.J.; Su, H.Q. $\mathrm{CeO}_{2}-\mathrm{CuO} / \mathrm{Cu}_{2} \mathrm{O} / \mathrm{Cu}$ monolithic catalysts with three-kind morphologies $\mathrm{Cu}_{2} \mathrm{O}$ layers for preferential $\mathrm{CO}$ oxidation. Appl. Surf. Sci. 2018, 434, 445-451. [CrossRef]

11. Shang, K.; Liao, W.; Wang, J.; Wang, Y.T.; Wang, Y.Z.; Schiraldi, D.A. Nonflammable alginate nanocomposite aerogels prepared by a simple freeze-drying and post-cross-linking method. ACS Appl. Mater. Interfaces 2016, 8, 643-650. [CrossRef] [PubMed]

12. Lee, K.Y.; Mooney, D.J. Alginate: Properties and biomedical applications. Prog. Polym. Sci. 2012, 37, $106-126$. [CrossRef] [PubMed]

13. Aime, C.; Coradin, T. Nanocomposites from biopolymer hydrogels: Blueprints for white biotechnology and green materials chemistry. J. Polym. Sci. Part B Polym. Phys. 2012, 50, 669-680. [CrossRef]

14. Chen, H.B.; Shen, P.; Chen, M.J.; Zhao, H.B.; Schiraldi, D.A. Highly efficient flame retardant polyurethane foam with alginate/clay aerogel coating. ACS Appl. Mater. Interfaces 2016, 8, 32557-32564. [CrossRef]

15. Safaei, M.; Taran, M.; Imani, M.M. Preparation, structural characterization, thermal properties and antifungal activity of alginate-CuO bionanocomposite. Mater. Sci. Eng. C 2019, 101, 323-329. [CrossRef]

16. Zhai, Z.; Ren, B.; Xu, Y.; Wang, S.; Zhang, L.; Liu, Z. Green and facile fabrication of Cu-doped carbon aerogels from sodium alginate for supercapacitors. Org. Electron. 2019, 70, 246-251. [CrossRef]

17. Carneiro-Da-Cunha, M.G.; Cerqueira, M.A.; Souza, B.W.S.; Carvalhoc, S.; Quintas, M.A.C.; Teixeira, J.A.; Vicente, A.A. Physical and thermal properties of a chitosan/alginate nanolayered PET film. Carbohydr. Polym. 2010, 82, 153-159. [CrossRef]

18. Grant, G.T.; Morris, E.R.; Rees, D.A.; Smith, P.J.C.; Thom, D. Biological interactions between polysaccharides and divalent cations: The egg-box model. FEBS Lett. 1973, 32, 195-198. [CrossRef]

19. Serrano-Aroca, A.; Ruiz-Pividal, J.F.; Llorens-Gamez, M. Enhancement of water diffusion and compression performance of crosslinked alginate films with a minuscule amount of graphene oxide. Sci. Rep. 2017, 7, 11684. [CrossRef]

20. Das, D.; Bang, S.; Zhang, S.M.; Noh, I. Bioactive Molecules release and cellular responses of alginate-tricalcium phosphate particles hybrid gel. Nanomaterials 2017, 7, 389. [CrossRef]

21. Matricardi, P.; Pontoriero, M.; Coviello, T.; Casadei, M.A.; Alhaique, F. In situ cross-linkable novel alginate-dextran methacrylate IPN hydrogels for biomedical applications: Mechanical characterization and drug delivery properties. Biomacromolecules 2008, 9, 2014-2020. [CrossRef] [PubMed]

22. Siqueira, P.; Siqueira, E.; de Lima, A.E.; Siqueira, G.; Pinzon-Garcia, A.D.; Lopes, A.P.; Segura, M.E.C.; Isaac, A.; Pereira, F.V.; Botaro, V.R. Three-dimensional stable alginate-nanocellulose gels for biomedical applications: Towards tunable mechanical properties and cell growing. Nanomaterials 2019, 9, 78. [CrossRef] [PubMed]

23. Liu, Y.; Zhao, X.R.; Peng, Y.L.; Wang, D.; Yang, L.W.; Peng, H.; Zhu, P.; Wang, D.Y. Effect of reactive time on flame retardancy and thermal degradation behavior of bio-based zinc alginate film. Polym. Degrad. Stab. 2016, 127, 20-31. [CrossRef]

24. Liu, Y.; Zhang, C.J.; Zhao, J.C.; Guo, Y.; Zhu, P.; Wang, D.Y. Bio-based barium alginate film: Preparation, flame retardancy and thermal degradation behavior. Carbohydr. Polym. 2016, 139, 106-144. [CrossRef] [PubMed] 
25. Zhang, J.; Ji, Q.; Wang, F.; Tan, L.; Xia, Y. Effects of divalent metal ions on the flame retardancy and pyrolysis products of alginate fibers. Polym. Degrad. Stab. 2012, 97, 1034-1040. [CrossRef]

26. Liu, Y.; Li, Z.F.; Wang, J.S.; Zhu, P.; Zhao, J.C.; Zhang, C.J.; Guo, Y.; Jin, X. Thermal degradation and pyrolysis behavior of aluminum alginate investigated by TG-FTIR-MS and Py-GC-MS. Polym. Degrad. Stab. 2015, 118, 59-68. [CrossRef]

27. Ma, X.M.; Li, R.; Zhao, X.H.; Ji, Q.; Xing, Y.C.; Sunarso, J.; Xia, Y.Z. Biopolymer composite fibres composed of calcium alginate reinforced with nanocrystalline cellulose. Compos. Part A Appl. Sci. Manuf. 2017, 96, 155-163. [CrossRef]

28. Liu, Z.Q.; Li, Z.; Yang, Y.X.; Zhang, Y.L.; Wen, X.; Li, N.; Fu, C.; Jian, R.K.; Li, L.J.; Wang, D.Y. A geometry effect of carbon nanomaterials on flame retardancy and mechanical properties of ethylene-vinyl acetate/magnesium hydroxide composites. Polymers 2018, 10, 1028. [CrossRef]

29. Wu, N.J.; Niu, F.K.; Lang, W.C.; Xia, M.F. Highly efficient flame-retardant and low-smoke-toxicity poly (vinyl alcohol)/alginate/montmorillonite composite aerogels by two-step crosslinking strategy. Carbohydr. Polym. 2019, 221, 221-230. [CrossRef]

30. Lewin, M. Some comments on the modes of action of nanocomposites in the flame retardancy of polymers. Fire Mater. 2003, 27, 1-7. [CrossRef]

31. Li, J.; Li, Z.; Zhao, X.; Deng, Y.; Xue, Y.; Li, Q. Flame retardancy and thermal degradation mechanism of calcium alginate/ $\mathrm{CaCO}_{3}$ composites prepared via in situ method. J. Therm. Anal. Calorim. 2017, 131, 2167-2177. [CrossRef]

32. Liu, Z.; Li, Z.; Zhao, X.; Zhang, L.; Li, Q. Highly efficient flame retardant hybrid composites based on calcium alginate/nano-calcium borate. Polymers 2018, 10, 625. [CrossRef] [PubMed]

33. Xu, P.; Shao, P.Y.; Zhang, Q.; Cheng, W.; Li, Z.C.; Li, Q. A novel inherently flame-retardant composite based on zinc alginate/nano-Cu $\mathrm{C}_{2} \mathrm{O}$. Polymers 2019, 11, 1575. [CrossRef] [PubMed]

34. Zhao, W.; Qi, Y.; Wang, Y.; Xue, Y.; Xu, P.; Li, Z.; Li, Q. Morphology and thermal properties of calcium alginate/reduced graphere oxide composites. Polymers 2018, 10, 990. [CrossRef] [PubMed]

35. Liu, Z.; Li, J.; Zhao, X.; Li, Z.; Li, Q. Surface coating for flame retardancy and pyrolysis behavior of polyester fabric based on calcium alginate nanocomposites. Nanomaterials 2018, 8, 875. [CrossRef]

36. Zhang, C.J.; Liu, Y.H.; Wang, L.; Zhu, P. Properties of $\mathrm{Cu}^{2+}$ modified calcium alginate fiber. Text. Aux. 2011, 1, 4 .

37. Zhang, H.Y.; Liu, C.J.; Chen, L.; Dai, B. Control of ice crystal growth and its effect on porous structure of chitosan cryogels. Chem. Eng. Sci. 2019, 201, 50-57. [CrossRef]

38. Yang, J.R.; Li, Y.Q.; Liu, Y.B.; Li, D.X.; Zhang, L.; Wang, Q.G.; Xiao, Y.M.; Zhang, X.D. Influence of hydrogel network microstructures on mesenchymal stem cell chondrogenesis in vitro and in vivo. Acta Biomater. 2019, 91, 159-172. [CrossRef]

39. Hou, X.; Xue, Z.; Xia, Y.; Qin, Y.; Zhang, G.; Liu, H.; Li, K. Effect of $\mathrm{SiO}_{2}$ nanoparticle on the physical and chemical properties of eco-friendly agar/sodium alginate nanocomposite film. Int. J. Biol. Macromol. 2019, 125, 1289-1298. [CrossRef]

40. Hou, X.B.; Xue, Z.X.; Xia, Y.Z. Preparation of a novel agar/sodium alginate fire-retardancy film. Mater. Lett. 2018, 233, 274-277. [CrossRef]

41. Kashiwagi, T.; Du, F.M.; Douglas, J.F.; Winey, K.I.; Harris, R.H.; Shields, J.R. Nanoparticle networks reduce the flammability of polymer nanocomposites. Nat. Mater. 2005, 4, 928-933. [CrossRef] [PubMed]

42. Papageorgiou, S.K.; Kouvelos, E.P.; Favvas, E.P.; Sapalidis, A.A.; Romanos, G.E.; Katsaros, F.K. Metal-carboxylate interactions in metal-alginate complexes studied with FTIR spectroscopy. Carbohydr. Res. 2010, 345, 469-473. [CrossRef] [PubMed]

43. Ramdani, Y.; Liu, Q.; Huiquan, G.; Liu, P.; Zegaoui, A.; Wang, J. Synthesis and thermal behavior of $\mathrm{Cu}_{2} \mathrm{O}$ flower-like, $\mathrm{Cu}_{2} \mathrm{O}-\mathrm{C}_{60}$ and $\mathrm{Al} / \mathrm{Cu}_{2} \mathrm{O}-\mathrm{C}_{60}$ as catalysts on the thermal decomposition of ammonium perchlorate. Vacuum 2018, 153, 277-290. [CrossRef]

44. Shi, R.; Tan, L.; Zong, L.; Ji, Q.; Li, X.; Zhang, K.; Cheng, L.; Xia, Y. Influence of Na (+) and Ca (+) on flame retardancy, thermal degradation, and pyrolysis behavior of cellulose fibers. Carbohydr. Polym. 2017, 157, 1594-1603. [CrossRef] 
45. Dong, Q.X.; Liu, M.M.; Ding, Y.F.; Wang, F.; Gao, C.; Liu, P.; Wen, B.; Zhang, S.M.; Yang, M.S. Synergistic effect of DOPO immobilized silica nanoparticles in the intumescent flame retarded polypropylene composites. Polym. Adv. Technol. 2013, 24, 732-739. [CrossRef]

46. Yang, C.Q.; He, Q.L.; Lyon, R.E.; Hu, Y. Investigation of the flammability of different textile fabrics using micro-scale combustion calorimetry. Polym. Degrad. Stab. 2010, 95, 108-115. [CrossRef]

(C) 2019 by the authors. Licensee MDPI, Basel, Switzerland. This article is an open access article distributed under the terms and conditions of the Creative Commons Attribution (CC BY) license (http://creativecommons.org/licenses/by/4.0/). 